\section{Molecular Syndromology}

Mol Syndromol 2010;1:87-90

DOI: $\underline{10.1159 / 000314268}$
Accepted: March 22, 2010

Published online: June 9, 2010

\title{
Identical Mutation in SH3BP2 Gene Causes Clinical Phenotypes with Different Severity in Mother and Daughter - Case Report
}

\author{
L. Preda ${ }^{a} \quad$ O. Dinca ${ }^{a} \quad$ A. Bucur ${ }^{a} \quad$ C. Dragomir ${ }^{b} \quad$ E. Severin ${ }^{c}$ \\ a Oral Surgery Department, ${ }^{b}$ Genetic Lab SRL, and ${ }^{c}$ Genetics Department, 'Carol Davila' University of \\ Medicine and Pharmacy, Bucharest, Romania
}

Key Words

Cherubism - Dental abnormalities - Enlarged jaw • SH3BP2

\begin{abstract}
Cherubism is a particular form of fibrous dysplasia of the jaws. Familial occurrence was reported in most cases. The condition is a rare hereditary disorder with autosomal dominant inheritance, with complete penetrance in males and incomplete penetrance in females and variable expressivity. It is known to be caused by mutations in the gene encoding SH3-domain binding protein 2, SH3BP2 gene. Major diagnostic criteria are cherubic facial appearance, painless hard enlargement of the jaws, and frequently associated dental abnormalities. The aim of the study was to analyze clinical and genetic features of cherubism in a family with 3 daughters in which the youngest one was affected. Clinical and radiographic examinations, hematological and biochemical evaluations and biopsy were performed. Molecular genetic analysis consisted of PCR amplification and direct sequencing of selected exons of the SH3BP2 gene. Cherubism was suspected based on clinical and radiographic examinations of the 9-year-old daughter. She presented asymmetrical enlargement of the mandible, speech and swallowing problems and dental abnormalities on the lower jaw. There was no history of similar clinical findings in any of the daughters or the par-
\end{abstract}

ents of the affected girl. Abnormal results were obtained by genetic analysis. A c.1244G $>$ A mutation was identified in exon 9 of the SH3BP2 gene in the asymptomatic mother and her affected daughter. The identified mutation in the SH3BP2 gene is probably disease-causing. The asymptomatic mother transmitted the gene mutation to her affected daughter. Our results confirm the reduced penetrance and variable expression of the gene mutation.

Copyright $\odot 2010$ S. Karger AG, Basel

Mutations in the SH3BP2 gene are known to cause a rare Mendelian disorder called cherubism (OMIM $\# 118400$ ). The incidence of cherubism is unknown. In 1933 W.A. Jones was the first who described the entity. Since then about 250 cases have been described worldwide. Recent literature in the PubMed database reports more new cases in the last years [Petschler et al., 2003; Fonseca et al., 2004; Brix et al., 2006; Lietman et al., 2006; Carvalho Silva et al., 2007; de Lange et al., 2007; Ueki et al., 2007; Lee et al., 2008; Carvalho et al., 2008, 2009]. No genotype-phenotype correlations have been described in the current literature.

By definition, cherubism is an abnormal hereditary condition characterized by progressive bilateral swelling at the angle of the mandible, especially in children. In

\section{KARGER}

Fax +41613061234 E-Mail karger@karger.ch www.karger.com

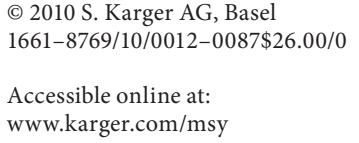

'Carol Davila' University of Medicine and Pharmacy

Faculty of Dentistry

24, Kiseleff str., RO-011346 Bucharest (Romania)

Tel./Fax +40 21222 6398, E-Mail severin.emilia@umf.ro 
Fig. 1. Facial appearance of the patient shows asymmetrical enlargement of the mandible.
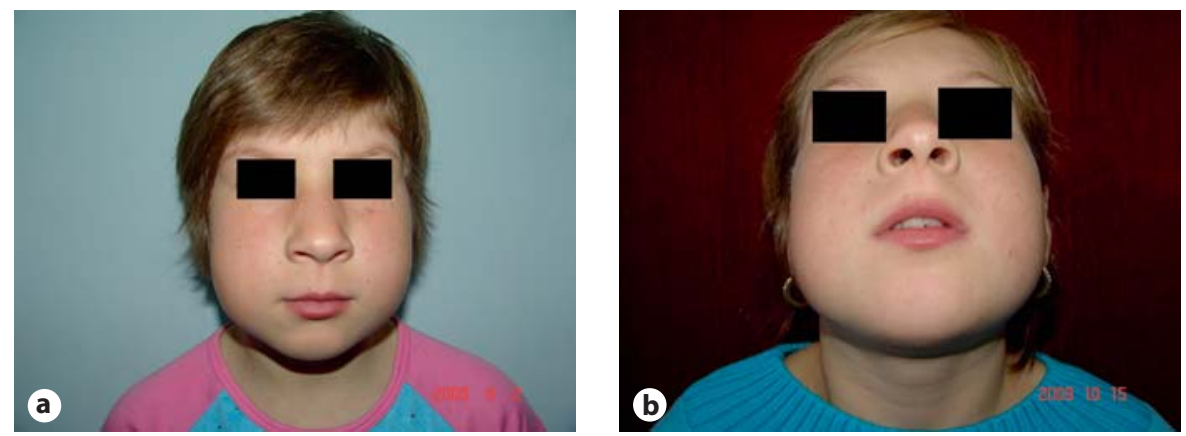

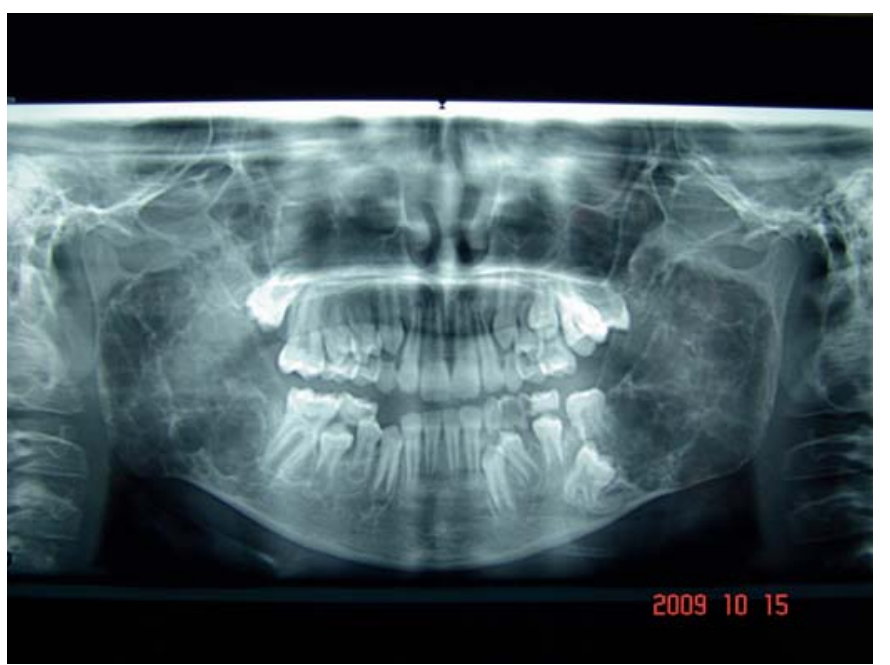

Fig. 2. Orthopantomogram of the patient shows bilateral multicystic lesions and dental abnormalities (agenesis of dental buds of 2nd and 3rd lower permanent molars); no similar lesions are seen in the maxilla.

।<smiles>C1CCCCC1</smiles>
1<smiles>CC1CCCCCC1C</smiles>

II

Cherubism with c.1244G>A mutation in exon 9 of SH3BP2 gene Asymptomatic with c.1244G $>$ A mutation in exon 9 of SH3BP2 gene

Fig. 3. Pedigree of the family.

some cases of cherubism, the entire jaw swells and the eyes turn up, enhancing the cherubic facial appearance. The condition tends to regress during adult life. The life span is not affected. Facial deformity may cause varying degrees of functional, cosmetic and psychological disability.

The World Health Organization included cherubism in a group of non-neoplastic bony lesions affecting only the jaws [Pindborg et al., 1971].

The aim of the study was to evaluate the genetic background and to identify the disease-causing mutation in the patient.

\section{Case Report}

A case of cherubism in a 9-year-old Caucasian girl is reported. The particularity of the case is the incomplete penetrance of the disease caused by a mutation in 2 female members of the same family and the possibility to under-diagnose the condition without molecular genetic testing

The patient was first seen in the Department of Maxillo-Facial Surgery in January 2009. She complained of painless, progressive and disfiguring enlargement of the lower face, speech and swallowing problems.

The mother told us that the patient is her third daughter. The girl had been born as a full-term normal delivery, with a birth weight of $3.100 \mathrm{~kg}$, following an uneventful but painful pregnancy. At birth, the baby girl showed normal facial appearance and no abnormalities were noticed throughout the next years. The girl was about 5 years old when her mother noticed the first signs of cherubism: the teeth were not in the right place on the mandible and, furthermore, there was an enlargement of the lower face. The enlargement was slow and progressive. The face became deformed, especially over the angles of the mandible.

Clinical examination revealed swellings at the angles of the mandible, a little asymmetrical enlargement of the mandible and chubbiness of the face (fig. 1). Mixed dentition and poor occlusion were noticed. No ocular, respiratory or cardiovascular problems were found. Except her facial appearance, bad alignment of the teeth and malocclusion, the patient did not exhibit any physical abnormality and showed no signs of mental retardation. 

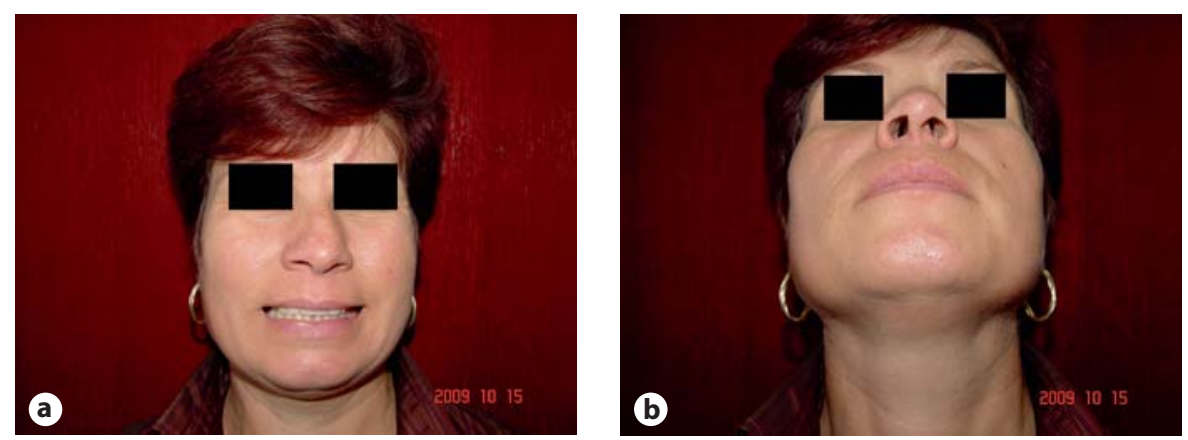

atic mother.

Panoramic radiograph showed clearly that the facial enlargement is the result of bone changes. Radiological examination revealed bilateral multilocular areas of diminished density in the mandible and congenitally missing 2 nd and 3rd lower molars. The maxillary dentition was not affected (fig. 2).

Biopsy of the mandible was obtained. Histological examination demonstrated the replacement of the normal bony structure with proliferating fibrous tissue containing numerous multinucleated acidophilic giant cells randomly distributed in a fibrovascular stroma of nuclear spindle-shaped cells [Cionca et al., 2009].

Family history was negative indicating no other members with similar findings (fig. 3). Both parents and their first 2 daughters are normal. The 2 nd daughter (age 14) of the couple had complications with the eruption of secondary teeth.

Cherubism was suspected based on suggestive clinical, radiological and histological findings.

The previous family history suggested a non-familial case of cherubism and a patient with an apparent de novo mutation. Diagnostic investigations were completed by molecular genetic detection for a SH3BP2 mutation. Informed consent for DNA analysis was obtained from all members of the family. Analysis consisted of PCR amplification and direct sequencing of exon 9 of the SH3BP2 gene, including the intron-exon boundaries. Of 5 family members, abnormal results were obtained for the patient and her mother. A c.1244G $>$ A mutation was identified in exon 9 of the SH3BP2 gene. Following the results, the 39-year-old mother was clinically and radiographically investigated. Facial appearance was unremarkable (fig. 4). Panoramic radiograph showed normal appearance of maxilla and mandible with no radiologic evidence of an earlier manifestation of cherubism in the jaws (fig. 5). There were no retrospective medical records or personal memories of any signs or symptoms of cherubism in her earlier years.

No operative treatment was undertaken. The patient was scheduled for regular follow-up (including clinical, radiographic, dental, orthodontic, and ophthalmologic evaluations).

\section{Discussion}

Despite a negative family history, genetic analysis was useful for the detection of familial mutation. Direct sequencing of exon 9 of the $S H 3 B P 2$ gene identified an A-

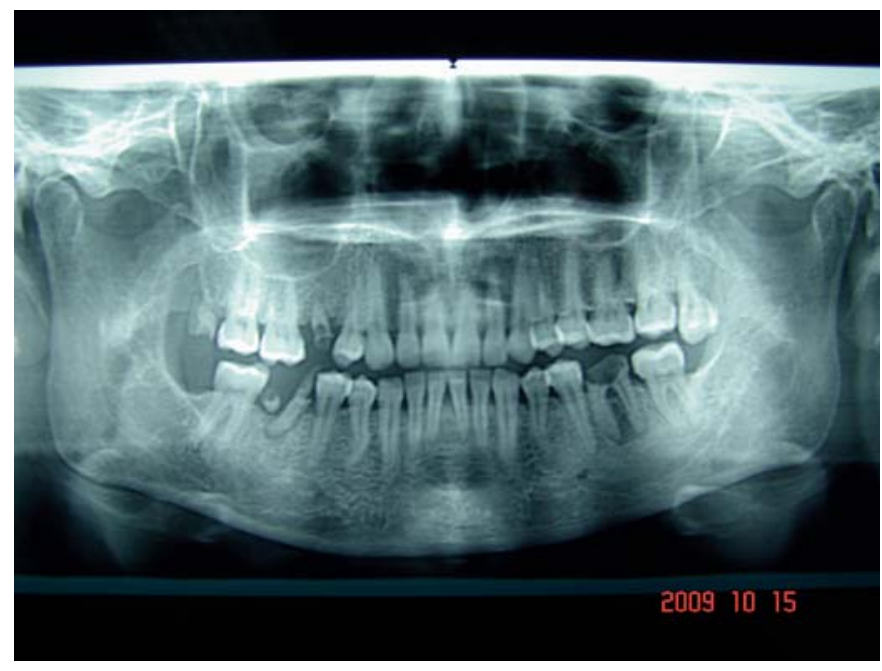

Fig. 5. Recent orthopantomogram of the mother shows normal radiological appearance without any remnants.

to-G transition, resulting in an arg415-to-gln (R415Q) substitution. This mutation was first reported by Ueki et al. [2001] in a family with a classical cherubic phenotype. It is described in the well-known mutation hotspot at amino acid number 415 to 420 [Ueki et al., 2001; Lo et al., 2003; de Lange et al., 2007; Carvalho et al., 2009]. All 11 missense mutations identified so far are in exon 9 and affect 4 amino acids within a 6-amino acid sequence (RSPPDG) located 31 to 36 amino acids upstream of the SH2 domain and 205 to 210 downstream of the SH3binding domain [Ueki et al., 2001; Lo et al., 2003; Lietman et al., 2006]. These results indicate an essential role of this domain of the gene in the development of cherubism.

Both patient and her mother carried the disease-causing mutation. The patient inherited the mutation from her mother in an autosomal dominant manner. The mother failed to express the clinical symptoms of 
cherubism whereas her youngest daughter expressed a mild cherubic phenotype with no sign of involvement of the maxilla or of the floor of the orbits. The effect of the lesions on permanent tooth development was manifested by absence of 2 nd molars and delay eruption of 1st molars in the mandible. This means that the SH3BP2 gene is linked to tooth development and eruption [Ueki et al., 2001; Hyckel et al., 2005]. The lack of signs in the carrier mother and the difference in clinical presentation between the patient and her carrier mother are consistent with incomplete penetrance in females and variable expression of the c.1244G $>$ A mutation in the SH3BP2 gene. We suggest that the mother was never afflicted by cherubism and did not develop the feature of the disorder in her youth based on recent jaw radiography and her information about her childhood. Radiological appearance was normal without any remnants. More than that, reduced penetrance in females is often observed in cherubism [Anderson and McClendon, 1962; Peters, 1979]. Recent studies demonstrated that even penetrance in males, thought to be close to $100 \%$, is incomplete [Petschler et al., 2003; de Lange et al., 2007]. Lietman et al. [2006] describe a c.1255G $>$ A mutation within exon 9 of SH3BP2 in a patient with cherubism. The patient's father and 2 siblings were carriers of the mutation but lacked clinical features of cherubism. Incomplete penetrance and variable expressivity of the mutation are explained by action of unidentified genes or other factors which may modulate the effect(s) of this mutation on the development of cherubism [Lietman et al., 2006].

We suggest genetic counseling/molecular genetic testing for all patients with cherubism, but especially for those with non-familial or sporadic forms.

\section{Acknowledgements}

We thank all the subjects for their participation in our study. We also thank Dr. Patrick Willems for his support and assistance.

\section{References}

Anderson DE, McClendon JL: Cherubism-hereditary fibrous dysplasias of the jaws. I. Genetic considerations. Oral Surg Oral Med Oral Pathol 15(Suppl 2):5-16 (1962).

- Brix M, Peters H, Rainfang E, Ricbourg B: Genetic aspects of cherubism. Rev Stomatol Chir Maxillofac 107:105-108 (2006).

-Carvalho Silva E, Carvalho Silva GC, Vieira TC: Cherubism: clinicoradiographic features, treatment, and long-term follow-up of 8 cases. J Oral Maxillofac Surg 65:517-522 (2007).

-Carvalho VM, Perdigão PF, Pimenta FJ, de Souza PE, Gomez RS, De Marco L: A novel mutation of the SH3BP2 gene in an aggressive case of cherubism. Oral Oncol 44:153-155 (2008).

- Carvalho VM, Perdigão PF, Amaral FR, de Souza PE, De Marco L, Gomez RS: Novel mutations in the SH3BP2 gene associated with sporadic central giant cell lesions and cherubism. Oral Dis 15:106-110 (2009).

Cionca FF, Cionca L, Vizitiu C, Ardeleanu C: Cherubism - case report. (abstract/European Journal of Human Genetics Vol 17, suppl 2), presented at European Human Genetics Conference, May 25, 2009, Vienna, Austria. Available at: https://www.eshg.org/eshg 2009/abstracts.htm de Lange J, van Maarle MC, van den Akker HP, Redeker EJ: A new mutation in the SH3BP2 gene showing reduced penetrance in a family affected with cherubism. Oral Surg Oral Med Oral Pathol Oral Radiol Endod 103: 378-381 (2007).

Fonseca LC, de Freitas JB, Maciel PH, Cavalcanti MGP: Temporal bone involvement in cherubism: case report. Braz Dent J 15:75-78 (2004).

Hyckel P, Berndt A, Schleier P, Clement JH Beensen V, Peters H, Kosmehl H: Cherubism New hypotheses on pathogenesis and therapeutic consequences. J Craniomaxillofac Surg 33:61-68 (2005).

Jones WA: Familial multilocular cystic disease of the jaws. Am J Cancer 17:946-950 (1933).

Lee JY, Jung YS, Kim SA, Lee SH, Ahn SG, Yoon $\mathrm{JH}$ : Investigation of the SH3BP2 gene mutation in cherubism. Acta Med Okayoma 62: 209-212 (2008).

Lietman SA, Kalinchinko N, Deng X, Kohanski $\mathrm{R}$, Levine MA: Identification of a novel mutation of $S H 3 B P 2$ gene in cherubism and demonstration that $S H 3 B P 2$ mutations lead to increased NFAT activation. Hum Mutat 27:717-718 (2006).
Lo B, Faiyaz-UI-Haque M, Kennedy S, Aviv R, Tsui LC, Teebi AS: Novel mutation in the gene encoding $\mathrm{c}$-Abl-binding protein SH3BP2 causes cherubism. Am J Med Genet A 121:37-40 (2003).

Peters WJN: Cherubism: a study of twenty cases from one family. Oral Surg 47:307-311 (1979).

Petschler M, Stiller M, Hoffmeister B, Witkowski R, Opitz C, Bill JS: Klinische und molekulargenetische Befunde bei Familien mit Cherubismus über 3 Generationen. Mund Kiefer Gesichtschir 7:83-87 (2003).

Pindborg JJ, Kramer IRH, Torloni H: Histological Typing of Odontogenic Tumors, Jaw Cysts, and Allied Lesions, in WHO International Histological Classification of Tumors series No. 5, 1st ed., pp. 18-19 (World Health Organization, Geneva 1971).

-Ueki Y, Tiziani V, Santanna C, Fukai N, Maulik $\mathrm{C}$, et al: Mutations in the gene c-Abl-binding protein SH3BP2 cause cherubism. Nat Genet 28:125-126 (2001)

Ueki Y, Lin CY, Senoo M, Ebihara T, Agata N, et al: Increased myeloid cell responses to $\mathrm{M}$ CSF and RANKL cause bone loss and inflammation in SH3BP2 'cherubism' mice. Cell 128:71-83 (2007). 